\title{
Technology, Entrepreneurship and Path Dependence: Industrial Clustering in Silicon Valley and Route 128
}

\author{
Martin Kenney a and Urs von Burg ${ }^{\mathrm{b}}$
}

(a'Department of Applied Behavioral Sciences, University of California-Davis, Davis, CA 95616, USA and ${ }^{b}$ University of St Gallen, St Gallen, Switzerland)

Silicon Valley and Route 128 have been the centers of innovation and commercialization for the electronics, computer and data communications industries in the postwar period. However, since the 1960s Silicon Valley has grown more rapidly and from approximately 1985 through 1995 Route 128 experienced retarded growth. Their success has diverged dramatically in the last decade. The most common explanations for this divergence are differing cultures, interfirm relations or/and internal organizational style organization. This paper builds upon path-dependent and dominant design explanations of technical and industrial change, arguing that the technological trajectories of the industries underlying the two regions were different and this led to their differential destinies. To explain the dynamics of the two regions, an analytical separation is made between the economy of the existing firms and a separate economy of institutions that evolved to nurture new firm formation.

\section{Introduction}

Silicon Valley and Route 128 occupy a special place in the cosmology of students of technological and economic development. It is no exaggeration to say that the firms started in these two regions after World War II have been critical actors and enormous beneficiaries of the increasing centrality of electronics in the global economy. In the process important new companies such as Apple Computer, Cisco Systems, Digital Equipment Corporation, Intel, Lotus and Sun Microsystems, to name only a few of the most salient, were established.

The two regions share similarities that make them seem to be an ideal paired case study to examine the effects of variables such as culture, industrial

(C) Oxford University Press 1999 
organization and technology in regional development (Saxenian, 1994). Before World War II neither region was central to the electrical and electronics industry, though both did have firms in these industries. Each region benefited greatly from Cold War military spending, though neither region was entirely dependent upon such spending (Markusen et al., 1991; Leslie, 1993). Each region has a pair of the finest research universities in the United States (though Harvard does not have engineering departments). Growth in their electronics industries has been driven by entrepreneurship. Today, both regions are global leaders with large pools of highly talented technical manpower, ample supplies of venture capital and infrastructures that encourage new firm formation.

The two regions grew rapidly in terms of both high-technology employment and new firm formation until the mid-1980s when both experienced serious setbacks due to dramatic cutbacks in defense spending, Japanese competition in a number of electronics fields, and for Route 128 the stagnation and decline of the minicomputer industry. By the early 1990s Silicon Valley began a major new spurt of growth and was only joined by Route 128 in the mid-1990s.

This paper does not intend to enter the debate about technological determinism versus social constructionism; however, we will argue that a technology's trajectory and potential are vital for understanding the fates of regional industries based on the technology. ${ }^{1}$ The evolution of each region displays important path-dependent characteristics as Route 128 evolved into the center of the minicomputer industry and Silicon Valley became the center of the semiconductor industry. The semiconductor would become the fundamental input to every product with an electronics function, whereas the minicomputer was a much more limited artifact. This is fundamentally important.

Dismissing the potential of the technologies that formed the industrial and innovative wellsprings for each region is simply untenable. The insistence that technology matters does not mean institutions and strategy are irrelevant. Rather it argues that social construction occurs within a context-and, in high-technology industries, technology counts. Put differently, Granovetter (1985) observes that firms are embedded in an institutional context and, of course, we accept this observation. However, one task in this paper is to demonstrate how the 'bed' was constructed. Without this constructional aspect, the bed is a static concept, and not terribly useful for analysis of emergent economic formations.

\footnotetext{
${ }^{1}$ Here we draw upon the formulations by Dosi (1984) and Dosi et al. (1994) regarding technological trajectories and regimes.
} 
Silicon Valley, especially, and Route 128 are peculiar because they are the home to large global corporations that compete in a number of hightechnology industries. And yet, these firms are not the mechanisms driving the economic future of either region. More important for the future are the institutions that have evolved to nurture new firm formation. Both regions have two linked, but analytically separable economies. There is one set of institutions or what we choose to call 'Economy 1' consisting of existing firms, corporate research laboratories and universities. There is a second Economy encompassing a variety of institutions specialized in facilitating new firm formation. Analytical separation of these two economies permits a more comprehensive understanding of the reasons for the dynamism of these two regions.

The paper begins by briefly discussing industrial clustering and previous studies of Silicon Valley and Route 128. Given the importance we attach to the technological underpinnings for the growth of the two regions, we introduce our distinction between Economy 1 and Economy 2 and briefly discuss the trajectories of semiconductors and minicomputers. In the third section the reasons for and dynamics of the growth of the semiconductor industry in Silicon Valley are presented. The fourth section follows with a similar discussion of the minicomputer industry in the Route 128 region. The following three sections illustrate the importance of Economy 2 in the process of industrial diversification in the two regions. Section 5 emphasizes the importance of other technology 'seed' institutions such as Xerox PARC and the IBM San Jose Laboratories, and argues that these institutions provided Silicon Valley with an important boost, especially since both regions have superb research universities. The sixth section discusses the creation of the local area networking (LAN) industry and the reasons Silicon Valley became the location of the dominant firms. Section 7 illustrates the limits of Silicon Valley and provides evidence that technologies and core competencies of industrial regions can, at times, be more important than particular organizational forms. The organizational forms can mutate to adjust to the technology. The final discussion gathers together the various strands of argumentation to illustrate how the evolution of these regions exhibits strong path dependence and postulates that the dynamism and self-renewal aspect of the two regions depends upon Economy 2. Finally, comparisons between the growth of the regions must explicitly consider the technological trajectories being tapped by the firms responsible for the growth.

\section{Previous Research}

There has been a general interest in the clustering of industries in specific 
geographical locations since, at least, Alfred Marshall. Recently, various economic geographers such as Walker $(1985,1988)$ and Storper and Walker (1989), evolutionary and path-dependence economists such as Arthur (1994) and David (1986), and business strategists such as Porter (1990) have developed explanations for this economic clustering. ${ }^{2}$ Arthur, in his explanation goes beyond agglomeration economies, to formally demonstrate conditions under which small events or historical accidents can be critical triggers that enable one region to become the center of a particular type of economic activity. Porter (1990) focuses upon the interrelationship between competing firms, supporting industries, the government and the market. All agree industrial growth in globally competitive regions is driven by economic benefits accruing from proximity.

Recently, greater attention has been given to explaining the industrial dynamics and the divergence in their performance of the two regions. ${ }^{3}$ Observers have credited various variables as critical to the high-technology development of these two regions including supplier networks (Saxenian, 1994), close proximity to research universities (Storper, 1993; Storper and Salais, 1997), labor mobility (Angel, 1990; Saxenian, 1994), cutting-edge technology, abundance of venture capital, and entrepreneurship (Gilder, 1989). Often the divergence is explained by significant differences in norms and behavior patterns exhibited by the firms in the respective regions. ${ }^{4}$ For some, these norms and cultural patterns are held to explain the willingness to create new firms (Weiss and Delbecq, 1990). These explanations are not simply scholarly constructions, rather they draw upon the observations of the actual participants.

In the first book-length account of the differences between the two regions Saxenian (1994; see also Saxenian, 1990) draws upon the cultural accounts, but goes further. In her formulation, the downturn both regions experienced in the mid-1980s occurred because their dominant firms became highly vertically integrated organizational structures honed for mass production and making them rigid, bureaucratic and oblivious to the external environment.

\footnotetext{
${ }^{2}$ The fundamental statement of evolutionary economics is Nelson and Winter (1982).

${ }^{3}$ Considering their importance to evolution of the electronics industry and the postwar US economy, the histories of Silicon Valley and Route 128 have received remarkably little study (for Silicon Valley, see Rogers and Larsen, 1984; Saxenian, 1994; Cringely, 1996; for Route 128, see Rosegrant and Lampe, 1992). Some of the most important studies that provide insight into Silicon Valley industry are those that examine various segments of the semiconductor industry (Braun and MacDonald, 1982; Reid, 1984; Riordan and Hoddeson, 1997) or the personal computer industry (Freiberger and Swaine, 1984). For Route 128 some of the most important materials are discussions of entrepreneurs or particular firms in the minicomputer industry (Kidder, 1981; Rifkin and Harrar, 1988; Kenney, 1992).

${ }^{4}$ These are often reduced to a vague and all-encompassing term called 'culture'. There are many reasons to be quite wary of such explanations because they are often devoid of any linkage to actual material activity, though these activities at a minimum condition the cultural arrangements.
} 
These dysfunctional structures were held to have deprived them of close customer contact and the external economies of flexible supplier networks. In this account Silicon Valley recovered because it abandoned this inflexible organization, which was only an aberration from its former reliance on flexible networks, and returned to its roots of flexibility and specialization. ${ }^{5}$ Route 128 firms traditionally relied, to a much greater extent, on vertical integration than Silicon Valley and were unable to renew themselves by building networks of flexible specialist firms. Undoubtedly, information sharing and interfirm cooperation have been important in Silicon Valley success, as they were in Route $128 .{ }^{6}$ While such relationships might explain the recovery of the existing firms, it does not address the ultimate reason for the industrial success of both regions - new firm formation.

The reasons for the establishment of new firms in the two regions is the focus of another genre of explanations. An empirical study of the creation and the survival of new semiconductor firms established in the USA from 1978 to 1986 led Schoonhoven and Eisenhardt (1989) to conclude that Silicon Valley is an 'incubator region' consisting of institutions that nurture the growth of small start-up firms. They attributed the higher survival rate of semiconductor start-ups in Silicon Valley to this incubator effect. Studying venture capital in both regions, Florida and Kenney (1988a,b) found what they termed a 'social structure of innovation', by which they meant an interactive set of institutions dedicated to encouraging technological innovation crystallized in new firms. ${ }^{7}$ On the basis of the difficulties both regions experienced in the late 1980s Florida and Kenney (1990) argued that this new firm formation process might actually prove harmful to the established firms-a conclusion that proved to be too pessimistic. More recently, Bahrami and Evans (1995) described Silicon Valley as an 'ecosystem' consisting of various institutions, skill sets embodied in individuals and an entrepreneurial spirit. These studies document an institutional environment that lowers the difficulty of launching a new technology firm. This is not a simple case of lowering entry barriers, it is also a matter of turbocharging early growth.

All business activity is dependent upon networks. Robertson and Langlois

${ }^{5}$ This argument has remarkable resemblance to the 'flexible specialization' formulation of Piore and Sabel (1984) that was said to be practiced in the high-fashion industries of Northern Italy. For critiques of the flexible specialization model, see Sayer and Walker (1992), Curry (1993) and Mueller and Loveridge (1995).

${ }^{6}$ This position is undoubtedly correct, though key suppliers are not confined to Silicon Valley, as R. Gordon (unpublished) points out these firms have global supplier chains. Stowsky (1987) also demonstrated the difficult relations between US semiconductor and equipment makers. Also, Florida and Kenney (1990a) point out the tensions in interfirm relationships in Silicon Valley.

${ }^{7}$ Lynn et al. (1996) advance yet another somewhat similar concept of an 'innovation community'; however. their concept is more general and seems to fit established industries better than it does environments such as Silicon Valley or Route 128. Also, it is not quite as explicitly spatial. 
(1995) conceptualize Silicon Valley and Route 128 as regions composed of networks able to mobilize the resources necessary to create a viable firm around a promising business opportunity. The Silicon Valley network structure is seen as an organizational response to the opportunities manifested in the turbulence of 'predominant design' stage environments when new technologies emerge (on dominant design, see Henderson and Clark, 1990). Robertson and Langlois (1995) find the stage in the product cycle influences the industrial organization. This links the product to the prevailing industrial organization, thereby assisting in explaining the differences that evolved between the semiconductorbased Silicon Valley and the minicomputer-based Boston area.

Previous research explains these two regions from a variety of perspectives. Some focus on the norms and culture encouraging new firm formation, while others emphasize the institutions that nurture new firm formation. The role of technological trajectories often receives little attention. For us, a critical feature in the dynamism of these two regions is, in a sense, not the existing firms, but rather the institutional complex specialized at creating new firms aimed at exploiting new technological innovations. In the next section we integrate the previous research and build a descriptive model.

\section{Silicon Valley and Route 128: A Model}

The emergence of new opportunities for new firm formation has occurred repeatedly in capitalism (Schumpeter, 1969). However, in most industries and regions an industrial maturation process occurred after which new firm entry ceased. The episodic and temporally bounded periods of innovation meant that no formal institutions evolved to benefit from and nurture the firm formation process. ${ }^{8}$ A constant flow of opportunities is critical because it is the substrate upon which institutions can be built to facilitate new firm formation.

The essence of both Silicon Valley and Route 128 lies in the continuous ability to create new firms. This process of establishing and nurturing new firms is correlated with the emergence of technological opportunities commercializable in small firms. ${ }^{9}$ For our purposes Silicon Valley and Route 128

\footnotetext{
${ }^{8}$ There have been sets of institutions created previously to facilitate investment in recurrent high-risk, high-return activities. For example, for long-distance trade to the East Indies in the 16-18th centuries in some European ports an entire infrastructure was created to finance, outfit and man such missions (Braudel, 1979). Another example is the network of institutions and financial backers that have arisen to support Broadway theatrical productions. Though, in these cases, the purpose was not to create firms, but rather to back individual high-risk projects.
}

${ }^{9}$ Some innovations do not lend themselves to commercialization in startups. Often, very expensive complementary assets are required for commercialization. For a general overview of this topic, see Dosi (1982). 
have two important sources of economic activity. The first source is the existing firms, some of which are growing very quickly-often even large firms are growing at greater than $25 \%$ per year. For example, the networking equipment company Cisco Systems has been growing at a $30 \%$ per annum compounded rate for 12 years. The established firms and institutions such as universities and corporate research laboratories are the critical components of what we term Economy 1. The other source of growth is a fabric of institutions that has evolved to encourage and nurture new firm formation. This we term Economy 2. Although Economy 1 and 2 are intimately linked, they are conceptually quite distinct.

Economy 1 encompasses the activities of the existing institutions, which deliberately, as in the case of corporate $\mathrm{R} \& \mathrm{D}$ laboratories, or as a by-product of their normal activities, as in the case of university laboratories, create seeds for spin-off entrepreneurship. In order to compete, established high-technology firms must continually invest in $\mathrm{R} \& \mathrm{D}$. The rapid pace of innovation in high-tech industry often creates technological discontinuities and new economic opportunities. With these technologies there are recurring periods when new opportunities emerge and very often the existing firms are unable to exploit all of the opportunities or simply miss the new opportunities because they are preoccupied with their current businesses (for a more general statement of this, see Christensen, 1997). Economy 1 also has a dense network of specialized suppliers supporting the existing firms (Saxenian, 1994). This is true for semiconductors, computer networking and hard disk drives (HDDs), to name some of the most prominent in Silicon Valley. In the Route 128 area this was true for minicomputers, though this supplier infrastructure was severely impacted by the crisis of the minicomputer industry.

Economy 2 is the institutional infrastructure aimed at the creation and growth of new firms (Todtling, 1994). For Economy 2, new firms are products that are roughly analogous to actual products like computers and microprocessors in Economy 1. In effect, the start-ups, which by definition are specialists, contain discrete packets of knowledge that their founders wish to exploit. One common source of start-ups are engineers who decide to commercialize a project that was blocked inside an established firm (Intel, 1984). After entrepreneurs, arguably, venture capitalists are the most critical actors in Economy 2 (Wilson, 1985; Florida and Kenney, 1999). Venture capitalists are financiers who invest in new firms in return for a partial ownership stake in the start-ups promising high growth rates and possibly huge capital gains. Ideally, venture capitalists hope to sell the start-up within 5-7 years either through an Initial Public Offering (IPO) or to an existing firm for a return of 
10 times their initial investment. Despite their hopes and machinations, the large majority of start-ups either fail entirely or remain small and stagnant, a category venture capitalists term 'zombies' or the 'living dead' (see Rogers and Larsen, 1984). The venture capitalists absorb failures because the profits from winners can be enormous. To provide an extreme example, Sequoia invested $\$ 2.3 \mathrm{~m}$. in Cisco Systems in 1987. When Cisco went public in February 1990 its capitalization was $\sim \$ 247 \mathrm{~m}$. and by June 1998 its capitalization had increased to $\sim \$ 80 \mathrm{~b}$. Sequoia Capital's share in the total value of Cisco after the public offering was $\$ 65 \mathrm{~m}$., an increase over the initial investment of nearly 30 times (Karlgaard, 1997). ${ }^{10}$

To prosper, Economy 2 depends on both entrepreneurs and a material basis to provide the large capital gains that drive it. Economy 2 was made possible by new firm formation, and through success transformed the environment into one even more conducive to new firm formation. ${ }^{11}$ To a large extent the entrepreneurs were drawn from the institutions of Economy 1, including established firms, universities and corporate research labs. Entrepreneurs leave their secure position in an established institution because of the potential for enormous capital gains. Also, the personal risks are not so high, because most of these entrepreneurs are highly successful managers or engineers who can easily find positions, if the start-up fails.

Various additional actors and institutions support Economy 2. There are law firms specializing in legal issues related to high-technology firms and venture capital. These include Wilson, Sonsini, Goodrich \& Rosati; Cooley Godward; and the Venture Law Group in the Bay Area. Another Bay Area law firm with a strong technology practice is Brobeck, Phleger \& Harrison. For Route 128 there are two law firms-Hale \& Dorr and Testa, Hurwitz, \& Thibeault - that have prominent high-technology practices, though they are not as specialized as some of the Silicon Valley law firms. These law firms assist fledgling start-ups not only in incorporation but also in handling delicate issues such as intellectual property. Often many very intricate and arcane legal issues arise when entrepreneurs attempt to commercialize technology developed at a previous employer (Suchman, 1995).

There are many other constituents of Economy 2. Marketing and public relations consulting firms, such as the McKenna Group in Silicon Valley, specialize in creating images for new firms. Regis McKenna, a former Fairchild marketing manager, is legendary for his work with Apple Computer

\footnotetext{
${ }^{10}$ If Sequoia's investors had retained their stock, in mid-1998 the value would have been in excess of $\$ 25$ b.

${ }^{11}$ The idea that environments are not the immutable selection mechanisms proposed by the social ecologists, but can actually be transformed to be more congenial to the supposed victims of selection is developed further in Florida and Kenney (1991).
} 
(Moritz, 1984; Rose, 1989). There are also a large number of executive search firms in both regions specializing in finding personnel for high-technology firms. They are retained by the firms, as well as by the venture capitalists.

In both regions, but especially in Silicon Valley, a number of investment banks-Hambrecht and Quist, Robertson Steffens, and Montgomery Securities in Silicon Valley; in Boston, First Boston Bank-developed skills in managing IPOs and analyzing high-technology stocks. ${ }^{12}$ The founders of these investment banks had close relationships with entrepreneurs and venture capitalists during the early days of the formation of Silicon Valley. For example, Sanford Robertson, one of the founders of Robertson Steffens, introduced the two founders of the venture capital partnership Kleiner Perkins to each other. Their partnership eventually expanded to become today's Kleiner, Perkins, Caufield and Byers-one of the most successful venture capital partnerships in history. Due to their proximity and personal relationships with venture capitalists and entrepreneurs, these boutique banks were able to wrest IPOs from their larger and more experienced New York competitors. Conversely, the existence of these boutique technology investment banks reinforced Economy 2 by providing local expertise on the legal and financial details necessary to go public. Proximity created relationships and saved time; it was no longer necessary to travel to New York to get advice and assistance. The response among the New York firms was to open Silicon Valley offices.

As Marshall said 'the secrets of the industry are in the air' (Foray 1991). There are many secrets, but the one thing that is not a secret is the centrality of capital gains as the fuel for Economy 2. All of the previously discussed institutions are more than willing to accept stock in at least partial compensation for their services. For the recipients this provides them with the opportunity to participate in the success of the firm, but it has a functional benefit for the start-up in that it decreases the start-ups' negative cashflow problems during its most difficult period.

An increasingly complex division of labor has evolved in Silicon Valley, and, to a lesser extent, in Route 128. For example, a recent Wall Street Journal article featured a consultant whose sole activity is preparing CEOs for their presentations to stock analysts before the company issues its IPO. The consultant was introduced to this opportunity through a venture capitalist, who believed there was a need for such a service. His consulting fee was \$20 000 and the right to purchase up to 1000 shares at the preoffering price in exchange for four days of training for the corporate officer (Hardy, 1998). The important

\footnotetext{
${ }^{12}$ Recently, these boutique investment banks have merged with much larger financial institutions seeking to a foothold in the high-technology field.
} 
issue here is not the fee, but the market for such a specialized skill and the consultants' interest in securing equity as part of his compensation. This illustrates Economy 2 perfectly. A specialized consultant finds a niche training executives to make the best possible presentation to stock analysts and portfolio managers before offering their company to the public. The consultant then receives partial payment in the form of stock.

Existing firms are members of Economy 1 but are critical for Economy 2. They supply inputs and supplies for start-up firms that allow them much more quickly to equip their operations and ramp-up production, thereby lowering barriers to entry. Often, the established firms are willing either to loan or provide very generous credit terms to small start-ups seeking to use their equipment.

Economy 2 evolved because the electronics technological paradigm provided so many recurring opportunities for entrepreneurs to create firms capable of growing very fast and within which innovation (or knowledge creation) could lead to enormous capital gains. The institutions evolved as pioneers adapted to their circumstances by creating mechanisms that satisficed. Put differently, they used the institutional materials at hand and refashioned them for their needs. These mechanisms, if successful, were reused and tweaked. Eventually, the successful experiments mutated into paths making the process clearer and more easily reproduced. In a word they became 'natural'. As is often the case in vibrant industrial ecologies, there was an ever greater division of labor as unique specializations emerged. The hothouse atmosphere of Economy 2 was fed by the constant new opportunities uncovered by the pace of change, and in a dialectic Economy 2's institutions demanded rapid growth from the firms it backed.

\section{Semiconductors and Minicomputers}

History is replete with examples of new technologies spawning new firms that coalesce into industries, so in this sense electronics is not unique (for the quintessential statement on this issue, see Schumpeter, 1969). A number of electronics innovations, such as the radio and television, provided windows during which non-incumbent electronics companies could begin producing the new innovation. However, as dominant design and product cycle theories suggest, the innovation process soon stabilized, many firms were shaken out and new firm formation slowed or even halted. ${ }^{13}$ In keeping with Nelson's

\footnotetext{
${ }^{13}$ For empirical confirmation of this, see the work of the institutional ecologists such as Hannan and Freeman (1989) or Aldrich and Fiol (1994).
} 


\section{Semiconductor}

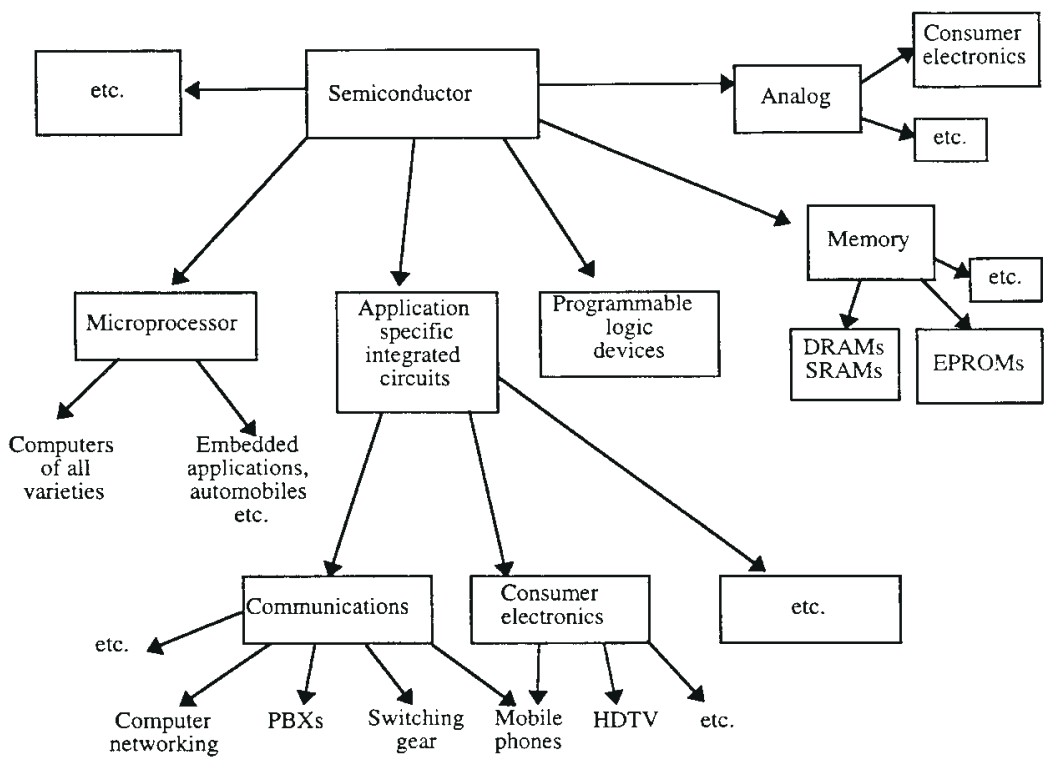

Minicomputer

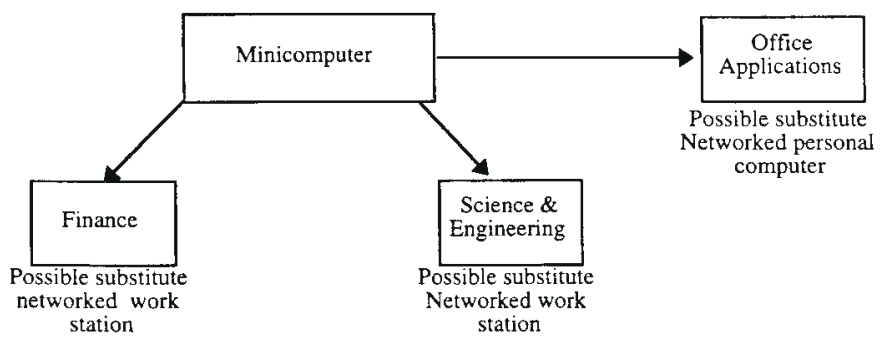

FIGURE 1. Applications of semiconductor and minicomputer technology. Source: author.

(1998) observation, our purpose is not to argue that technology determines the fate of firms, industries or regions, but rather to argue that the trajectory does matter in conditioning the possibilities and even the organizational forms created to exploit the technology.

The fundamental differences between semiconductors and minicomputers provide critical insight into understanding the differences in the two region's respective technological trajectories (Robertson, 1995). Figure 1 illustrates the critical difference between the role of the semiconductor as a component and the minicomputer as an assembled machine. As a transistor, a semiconductor was a simple component. But in its incarnation as an integrated 
circuit, it is a complicated device embodying sophisticated knowledge in an inexpensive physical material, silicon. The potentiality of the semiconductor was expressed well in an early display of 'silicon chauvinism' by Floyd Kvamme, a National Semiconductor executive, in an interview in the early 1970s, 'Any product that uses springs, levers, stepping motors or gears is performing logic and that product should be built of semiconductors' (Braun and Macdonald, 1982, p. 104). In retrospect, Kvamme was much too modest.

The semiconductor was invented at Bell Laboratories in the late 1940s and was then quickly commercialized. Beginning with the transistor and then evolving to the integrated circuit, as a product semiconductors exhibited some unusual properties, the most significant of which for our discussion is that production experienced extremely steep learning curves. With these learning curves it was possible to constantly lower the price of a particular model until it was superseded by a more powerful model. Braun and Macdonald (1982) illustrate this with the example of a Fairchild transistor that sold in 1959 for $\$ 19.75$ and in 1962 cost only $\$ 1.80$; despite such price declines semiconductors were extremely profitable (Gilder, 1989). Gordon Moore, one of the founders of Fairchild and later Intel, observed that the number of transistors on an integrated circuit (a rough approximation of the functionality of an integrated circuit) doubled approximately every 18 months — this came to be called Moore's Law. The result of this law, which is really an observation about the rate of technical change, is that there is a constant unfolding of opportunities to apply integrated circuits to new uses. ${ }^{14}$ Since most physical phenomena can be rendered digitally with sufficient calculating power, Moore's law described the growth in this power. The result has been a continuous onrush of newly emergent opportunities for integrated circuitry.

More recently, another technological trajectory is motivating new firm formation. Gilder (1996) calls this Metcalfe's Law: it postulates that the value of a network is roughly proportional to the number of users squared. ${ }^{15}$ These two trajectories are joined by the fact that areal density of magnetic memory is doubling every 18 months or less. The combination of Moore's Law and Metcalfe's Law and the dramatic decrease in the cost for the transmission of bits has opened economic spaces in which entrepreneurs have been able to build new businesses, some of which experience extremely rapid growth.

In the postwar electronics industry, transistors and then integrated circuits were an enabling technology for nearly every important electronic innovation.

\footnotetext{
${ }^{14}$ For an insightful discussion of the implications of Moore's Law, see Schaller (1996). He argues rightly that this was not a 'law' in the physical sense, but rather an empirical observation about the rate of change.

${ }^{15}$ Robert Metcalfe was the inventor of Ethernet at Xerox PARC and then founded one of the largest computer networking firms in the world, 3Com.
} 
For example, DEC's first minicomputer was predicated upon the availability of transistors (Olsen, 1983). ${ }^{16}$ The personal computer and workstation were a direct result of the invention of the microprocessor by Intel. Computer networking would not be possible without sophisticated integrated circuitry to process and direct the data.

In contrast, the minicomputer is only a segment of the entire computer industry. Before minicomputers, computing was done on large, expensive mainframes serving entire companies. The typical mainframe cost upwards of $\$ 1 \mathrm{~m}$. and was housed at a special computer facility; users had to physically deliver their punch cards to the computer operator. The minicomputer drew upon innovations such as the transistor, less expensive magnetic memory and the modem to build a computer costing a couple hundreds of thousands of dollars and capable of being accessed from the user's desktop through a modem (i.e. timesharing, another business field in which Economy 2 reaped considerable capital gains). The minicomputer industry sold machines that could be purchased and used by corporate departments. Viewed from a long-term perspective, minicomputers were a step on the road to providing computing power to everyone-what has recently been termed 'ubiquitous computing'.

The minicomputer substantially widened access to computing, helping the computer to penetrate financial, scientific and office worksites through time-sharing utilization of computers at remote sites. ${ }^{17}$ The minicomputer experienced a steep cost-performance improvement curve, but the architecture of its market niche stymied its greater diffusion. In the mid-1980s the limit of the minicomputer paradigm became apparent as workstations appeared that offered similar computing power for $20 \%$ of the cost of a minicomputer (Hall and Barry, 1990, p. 79; Garud and Kumaraswamy, 1993; Baldwin and Clark, 1995). By the beginning of the 1990s, due to the severe competition from workstations, the market for minicomputers stagnated and many minicomputer companies failed.

The intimate relationship between these economies and their core technologies is conditioned by two caveats. First, though the regions were the centers for their respective technologies, other regions had rival firms. Second, neither region's electronics industries were confined to a particular technology. Silicon

\footnotetext{
${ }^{16}$ DEC purchased its first box of 1000 transistors for $\$ 12500$; before they used them the price of the same box of 1000 had dropped to $\$ 8000$ (Olsen, 1983). This was a harbinger of what became routine in the semiconductor industry.

${ }^{17}$ One unheralded contribution of the greater access provided by the minicomputer is that many of the leading desktop computing innovators, such as Bill Gates and Paul Allen, learned their computing skills on time-shared minicomputers.
} 
Valley, especially, and Route 128 had entrepreneurial success in other electronics industry segments.

This section illustrated the important differences between the technological trajectories of semiconductors and minicomputers. First, the semiconductor found a far greater variety of applications than did the minicomputer-this is not entirely surprising as one was a component and the other a finished machine. Of course, the semiconductor encompasses a broad class, somewhat analogous to the computer. Interestingly, with the exception of IBM, no computer maker has been able to effectively migrate to new classes of computers. For the growth of Silicon Valley the semiconductor was important because it made so many other products possible, such as personal computers, workstations, computer networking devices and many more. The close proximity of semiconductor manufacturers allowed significant information transfer to occur, giving Silicon Valley entrepreneurs a significant jump on entrepreneurs and established firms in other regions.

\section{Silicon Valley and Semiconductors}

The Santa Clara Valley and semiconductors have not always been synonymous. However, even before World War II, a number of innovative electrical and electronics firms had been established in the Bay Area. Many of these companies were purchased by larger established East Coast firms and relocated. Just before and during World War II still more small firms, such as Hewlett Packard and Ampex, were established and located in the South Bay region (we will use the shorthand: Silicon Valley). World War II was a boom period for these firms as they grew quickly on the back of lucrative military contracts (Rogers and Larsen, 1984; Sturgeon, 1992). As part of his strategy, which began before World War II, to build a Bay Area electronics industry, Frederick Terman, then Dean of Engineering at Stanford University and later Provost, encouraged the formation of electronics firms and the location of corporate research labs in the Palo Alto area. By the early 1950s a small number of firms, including Hewlett Packard, Litton and Varian, were operating in Silicon Valley (Lowen, 1992; Leslie, 1993; Saxenian, 1994). The continuing military spending during the Cold War created a large market for electronics devices and the firms grew steadily. And yet, by the mid-1950s Silicon Valley electronics employment remained small in comparison to Route 128 (or even Chicago, one of the centers of the consumer electronics and vacuum tube industries). At this point there was no critical core technology or anything in particular to distinguish Silicon Valley from other regions with 
greater concentrations of engineers and research facilities such as northern New Jersey and Los Angeles.

In 1955 William Shockley, co-inventor of the transistor at Bell Laboratories, decided to start a firm to exploit his device. But to start a firm he needed capital. He approached a number of organizations on the East Coast about funding his proposed start-up. In particular he negotiated with Raytheon, the important Boston area high-technology manufacturer, founded by MIT professor Vannevar Bush and an early entrant and then leader in transistor production. He demanded $\$ 1 \mathrm{~m}$., but after a month of bargaining Raytheon refused (Scott, 1974, p. 305). He also negotiated with the Rockefeller venture capital arm, but no agreement could be reached. After these failures he was introduced to Arnold Beckman, the founder of Beckman Instruments in Los Angeles. They reached an agreement and Beckman agreed to fund Shockley to start a firm in Palo Alto (Riordan and Hoddeson, 1997). ${ }^{18}$ As fate would have it, the failure on the East Coast would have great regional consequences.

Shockley hired eight brilliant young scientists and engineers. However, Shockley proved to be an ineffective manager and the eight resigned in 1957 to form their own start-up. They received funding from an East Coast firm, Fairchild Camera and Instrument Company, owned by Sherman Fairchild. Fairchild's founders began employing silicon to create transistors, an innovation they had proposed to no avail at Shockley. Fairchild quickly became a technological leader in the transistor industry and spearheaded the transition to the integrated circuit. In 1960 Jean Hoerni, one of the Shockley defectors, invented the planar process that made mass production possible (Rogers and Larsen, 1984) and a cascade of innovations followed.

Fairchild had been established at ground zero of one of the most important technological developments of the twentieth century, the integrated circuit. When Fairchild Camera and Instrument Corporation provided capital to Fairchild Semiconductor's founders, one clause in the agreement gave it the option to purchase the founders' shares of Fairchild Semiconductor within three years for $\$ 3 \mathrm{~m}$. Quite naturally, as the firm was immediately profitable and the market boomed, Fairchild exercised its option and the founders lost their equity participation in the company.

With the Sputnik-related military build-up throughout the 1960s and the adoption of transistors and integrated circuits in the consumer electronics and computer industries, sales boomed and profits were exorbitant (Hanson, 1982). As is usual in capitalist economies, these high profits attracted firms from a variety of other industries. Entry into the arcane field of

\footnotetext{
${ }^{18}$ Initially, Beckman wanted Shockley to establish the firm in the Los Angeles area.
} 


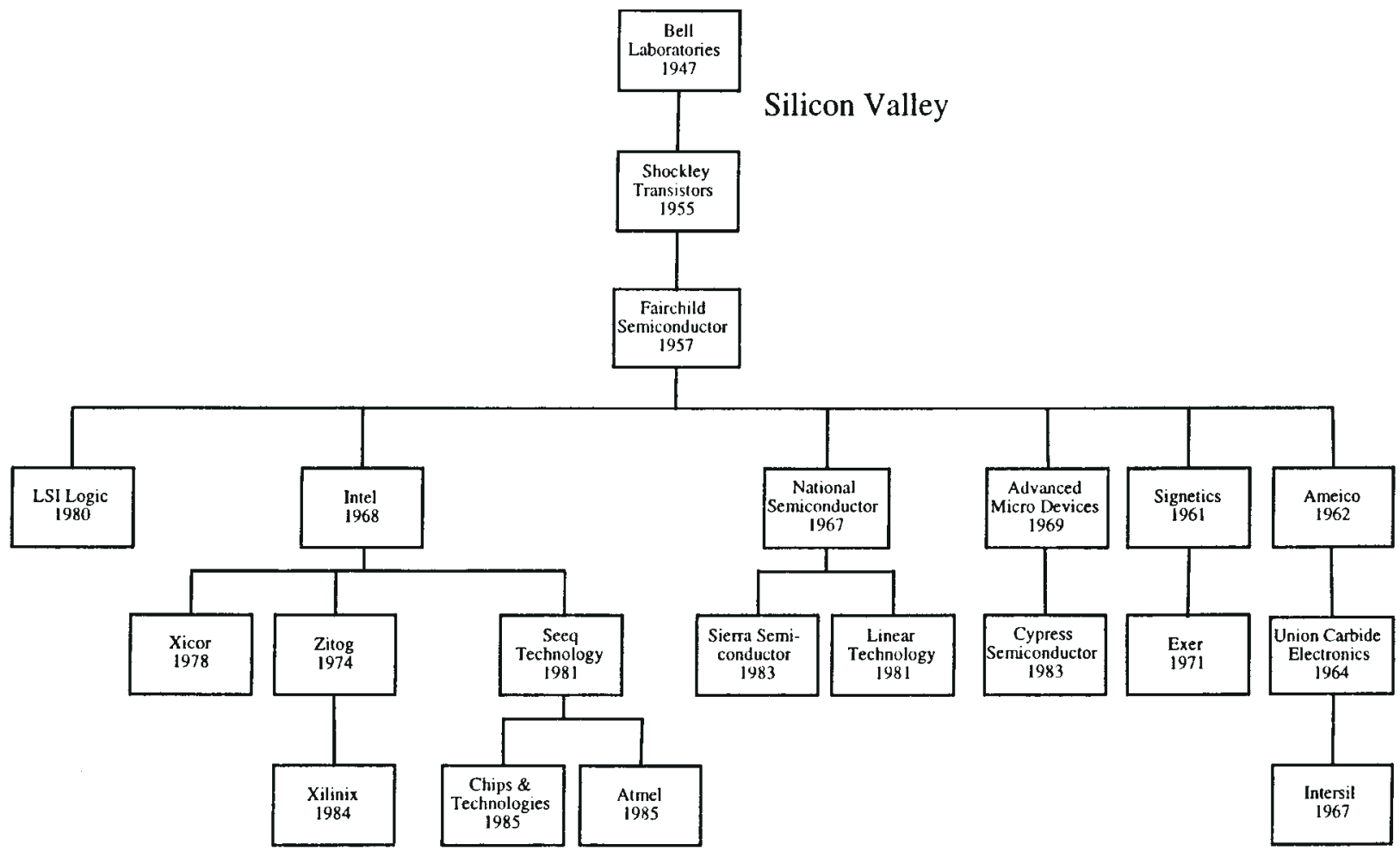

FIGURE 2. Genealogy of Silicon Valley start-up semiconductor firms. Source: adapted from Semiconductor Equipment and Materials Institute (1987) and various oher sources. 
semiconductors required trained personnel, but due to the intense labor shortages, it was difficult simply to hire electrical engineers and especially semiconductor design engineers. In such an environment experienced engineers and managers were in a strong bargaining position and the most desirable incentive was equity, because it allowed recruits to share in the success of the firm. During this early period many start-ups were funded by established firms aiming to create a semiconductor division; in part this was because venture capital investment was still in its infancy. The electronics industry would experience recurring bursts of hiring manias as firms strained to keep up with the possibilities.

As a by-product of the exuberant growth of the semiconductor industry in the 1960s many firm founders and early employees became very wealthy (Tilton, 1971, p. 80). Their success put in motion a path-dependent logic, both in terms of an example and an incentive for others to follow and establish their own firms. ${ }^{19}$ This process is illustrated in Figure 2, which is an abbreviated genealogy of Silicon Valley semiconductor start-ups through 1986 indicating some of the listed 124 start-ups whose roots have been traced to Fairchild. Robert Noyce, a founder of Fairchild and Intel, described dilemmas faced by the firms on the cutting edge of the semiconductor industry as a situation in which so many commercial opportunities were being created that there was no way for one company to take advantage of them all. This provided the perfect stimulus for teams of engineers with rejected projects to resign and create their own firm.

Fairchild also contributed individuals to two other important Silicon Valley businesses. The first is the semiconductor equipment and materials firms which were critical for the actualization of Moore's Law and the rapid progress of the semiconductor industry (Lindgren, 1969, p. 5; see also Stowsky, 1987). For example, Gordon Moore (personal communication, 1997) recounts how a technician who made capillary tubes for a gold-bonding process spun-out to establish Electroglass Inc., a company specialized in building semiconductor furnaces. The clustering of the semiconductor equipment industry in Silicon Valley reinforced the continued success of the semiconductor cluster by deepening the local knowledge base. ${ }^{20}$ Equipment makers are critical for enabling production and as conduits for information transfer and innovation. ${ }^{21}$ Still later, a number of integrated circuit design

\footnotetext{
${ }^{19}$ Kogut et al. (1991) found a significant regional correlation between the presence of large semiconductor firms and startups.

${ }^{20}$ For a general discussion of this mutual reinforcement process between industries and supporting industries, Porter (1990).

${ }^{21}$ The importance of the relationship between manufacturers and equipment makers is not unique to semiconductors, but, as von Hippel (1988) points out, is a more general phenomenon.
} 
software firms, such as Cadence and Synopsys, were established in Silicon Valley. ${ }^{22}$

The second industry in which alumni from Fairchild and its spin-offs were important was the venture capital business. In addition to Arthur Rock-who arranged the Fairchild investment in 1958 and organized the funding for Intel and many other start-ups, such as Apple and Scientific Data Systemsother important venture capitalists who began their career at Fairchild are Donald Valentine and Pierre Lamond of Sequoia Partners, and Eugene Kleiner of Kleiner Perkins; Floyd Kvamme of Kleiner Perkins is an ex-National Semiconductor executive. ${ }^{23}$ And, perhaps more important, the success of Fairchild's spin-offs (such as Intel, Advanced Micro Devices, National Semiconductor, LSI Logic and their own spin-offs) created enormous capital gains for their founders, key employees and investors in venture capital funds. Some of these gains were reinvested in venture capital funds and independent start-ups. The final important contribution of Fairchild and its early start-ups were managers and engineers who had become independently wealthy and were able to invest in or even join start-ups without risking their financial health. ${ }^{24}$

Fairchild was a critical firm not only because it was the source of so many entrepreneurs, but also because it was a monument to how not to manage a firm in the semiconductor industry. The lesson to the entrepreneurs and investors was that all key employees must share in wealth creation. The stock option became the method of choice for compensating and retaining key employees. Some firms went further and gave stock options to every employee.

Fairchild's exodus galvanized the firm-creation process that cemented Silicon Valley's lead in the semiconductor industry and triggered the evolution of a regional venture capital industry. Initially, many Silicon Valley deals had to include East Coast investors such as the Rockefellers, the Whitneys and individuals such as Fred Adler, because there was insufficient capital on the West Coast. However, due to the early successes capital accumulated quickly in Silicon Valley. Furthermore, West Coast venture capitalists recognized that the East Coast firms were garnering large capital gains while only providing funds, and were doing little of the legwork in finding entrepreneurs and

${ }^{22}$ Synopsys was founded in North Carolina by engineers spinning out of GE's semiconductor design group and was moved to Silicon Valley by their venture capitalists.

${ }^{23}$ This is best illustrated in the 'Genealogy of Silicon Valley Venture Capitalists' chart prepared in the mid-1980s by the Silicon Valley venture capitalist, Franklin 'Pitch' Johnson's wife, Cathie Johnson.

${ }^{24}$ Some important Fairchildren who played important roles in startups outside of the semiconductor and venture capital industries include the already mentioned Michael Markkula, a founding partner in Apple, and William Mitchell, one of the founders of Seagate. 
taking the risks in the earliest stages. In response, West Coast venture capitalists organized their funds as limited partnerships to amass larger blocks of capital. Eventually, the East Coast venture capitalists established branch offices on the West Coast to secure access to the deals.

The enormous capital gains of the early investments quickly produced a self-reinforcing process. Successful venture capitalists reinvested their capital and again experienced very good returns; new venture capitalists entered the field; and investors provided ever larger sums to venture capital funds. In 1969 , private institutions committed $\$ 171 \mathrm{~m}$. in new capital to venture capital funds, and there were 150 venture capitalists in the Bay Area (Rogers and Larsen, 1984; Saxenian, 1994); by 1997 more than $\$ 3$ b. was invested. Not surprisingly, the broad availability of venture capital reinforced the firm-creation process, which, in turn, spurred the accumulation of venture capital. To sum up, Fairchild's lead in semiconductor technology and the perennial exodus of talented personnel from established firms initiated mutually reinforcing processes of firm creation, venture capital formation and rapid technological development. As a result, by the late 1970s Silicon Valley had become the leading center for semiconductor technology.

\section{Boston and Minicomputers}

Before World War II there were already some high-technology electronics firms in the Boston area. The most prominent of these was Raytheon, founded in 1922 (under the name American Appliance Company) to develop a thermostat, but then switched to vacuum tubes (Scott, 1974). During and immediately after World War II, Boston civic leaders, concerned over the decline in New England industry, decided to establish the first organized venture capital firm, American Research and Development (ARD) to provide funding to entrepreneurs (Liles, 1977). In the early postwar years there were a number of start-ups aimed at providing various high-technology products for the defense industry, though there was no discernible theme to this cluster of firms beyond the fact that many of the entrepreneurs were MIT graduates. In 1951 An Wang opened Wang Laboratories to make core memories for computers and undertook a variety of electronics-related projects (Kenney, 1992). But in 1955 there was no reason to believe that the Boston area would become an electronics industry center.

The first minicomputer company, Digital Equipment Corporation (DEC), was founded in 1957 on Route 128 by Kenneth Olsen who had developed the minicomputer concept at MIT's Lincoln Laboratories (Rifkin and Harrar, 1988). For $\$ 70000$ and a $\$ 30000$ loan DEC gave $70 \%$ of the firm to ARD 
(Dorfman, 1987). During the early days of the minicomputer industry a spinout process similar to the one in semiconductors developed. DEC and the other Route 128 minicomputer companies became the source of many start-ups. Romanelli (1987, p. 166) found:

Nearly 60 firms were founded during the late 1960s and early 1970s to produce minicomputers. The majority were started by engineers who had worked for DEC or other minicomputer producers. Typically, engineers founded new companies in order to design minicomputers that their former employers would not support. This scenario is reminiscent of Silicon Valley. However, by the late 1970s the minicomputer industry stabilized and new entrants faced entrenched rivals.

Silicon Valley firms also produced minicomputers (Tandem Computers and Hewlett Packard), but the recognized center of the minicomputer industry was Route 128, which was responsible for $60 \%$ of total US production in 1982 (Hekman, 1980; Dorfman, 1982, 1983). ${ }^{25}$ The Route 128 area quickly spawned an infrastructure of suppliers, consultants, software programmers, etc., to support the minicomputer industry (Dorfman, 1982; Kuhn, 1982). In 1966 a study comparing the environment of forming science-based industries in Philadelphia and Boston found far greater access to venture capital in Boston and there was already a community of start-ups that encouraged more start-ups (Deutermann, 1966).

As the industry matured, its industrial organization changed. In the 1970s minicomputer companies vertically integrated to reduce supply uncertainties, especially for key components such as integrated circuits and HDDs. ${ }^{26}$ DEC was able to reduce its turnaround time by $20 \%$ by designing and manufacturing its own integrated circuits (Kuhn, 1982, p. 31). Another reason for producing integrated circuits internally was that the design was a critical intellectual property, which could be lost if the outside supplier decided 'to produce the specialized component for the commercial market or to integrate forward, putting itself in competition with its original client' (Kuhn, 1982, p. 32). ${ }^{27}$ Finally, the minicomputer firms wanted to capture the

${ }^{25}$ SDS, another minicomputer firm founded in El Segundo, California, was later purchased by Xerox, and then failed spectacularly (Levering et al., 1984; Flamm, 1988).

${ }^{26}$ This is not unique to minicomputers and the Boston area. Intel, the world's largest semiconductor maker, is highly integrated, fabricating almost all of its chips, assembling most of them, using many of its own integrated circuit design software programs, and even building its own PC motherboards. Seagate, the world's largest HDD producer is highly vertically integrated. Moreover, both companies show no signs of disintegrating.

${ }^{27}$ A wisdom that IBM forgot to its everlasting regret, when it created an open, but owned system in its PC software and microprocessor. In the same way, today Intel fabricates all of its microprocessors internally, thereby providing the intellectual property in its microprocessors greater protection. For the 'open but owned' distinction, see Borrus and Zysman (1997). 
profits that normally went to suppliers and there was substantial value in the components. Not only did many, but not all, Route 128 companies vertically integrate, so did minicomputer companies in other regions. Curiously, when the minicomputer industry collapsed it was the other capabilities, such as networking and systems integration expertise, semiconductor design and HDD capabilities, that were their most valuable assets.

The demise of the minicomputer industry has its roots in its success. In the late 1970s DEC developed the tremendously successful VAX strategy for fully compatible networked minicomputers (Rifkin and Harrar, 1988). This growth created an environment within which all minicomputer firms understandably, but mistakenly, initially dismissed the importance of the then-fledgling microcomputer and workstation industries. DEC and especially Kenneth Olsen are often singled out for not comprehending the potential of desktop computing to transform the computer industry. Olsen was not alone. For example, An Wang also believed desktop computers had little future (Kenney, 1992). This lack of vision gives credence to Saxenian's argument that Route 128 was too vertically integrated and not flexible enough to see the importance of personal computers. However, even the perennially best managed firm in Silicon Valley, Hewlett Packard, which had the benefit of both a large electronic calculator division, a minicomputer business and Steven Wozniak as an employee, was also slow in entering the PC and workstation businesses (Moritz, 1984, p. 126; Malone, 1995).

In the mid-1980s the minicomputer industry experienced pressure on sales from workstations built around high-speed microprocessors. These workstations connected to LANs gave near-minicomputer performance on the user's desk at a much lower cost. Given these advantages, the minicomputer firms' market share was eroded by the less expensive workstations. Essentially, the difficulties experienced by the minicomputer firms were the result of the deterioration of their technological paradigm. In hindsight it is easy to say that the minicomputer firms foolishly did not advance quickly enough into the workstation business, but actors rarely have perfect foresight. Despite a wide variety of organizational structures in the minicomputer industry and varying types of relationships with suppliers, it is not clear that any specific industrial structure or set of interfirm relationships could have prevented the decline of the minicomputer industry or that they would have been able to protect their position by entering the desktop industry.

The stagnation of the minicomputer industry combined with the end of the Reagan administration military buildup had a severe effect on the Route 128 economy. Even though Route 128 has a number of very successful electronics companies in 1998, it has no powerful core industry in which its firms are 
globally dominant. This is a fundamental difference between Silicon Valley and Route 128 today.

\section{Regional Diversification}

Each region had a core industry, but both also diversified. The seeds for diversification came from the various institutions of Economy 1. The role of the major research universities in providing seeds for new industries is already well-known (for Route 128, see Roberts, 1991; for Silicon Valley, see Saxenian, 1994). Similarly, we have also discussed the role of spinouts from the ongoing development activities of established firms. The other set of institutions that contributed the seeds for building new industries are the corporate research laboratories in Silicon Valley, and their greater presence in Silicon Valley than in Route 128 has made an important difference by providing the technological seeds for the development of other electronics industry segments.

In 1952 IBM located the first major electronics research center in San Jose. IBM's goal was to secure access to talented West Coast engineers unwilling to relocate to its East Coast research laboratories (Mayadas, 1998). The San Jose laboratory had IBM's global mandate for magnetic data storage research, and its neighboring factory was responsible for magnetic storage device manufacturing. Many of the innovations that Silicon Valley HDD start-ups would later commercialize came from IBM's research laboratory. Magnetic storage manufacturing and marketing operations were also located on the site and could be raided for the necessary managers to build a complete start-up. Thus, it is no surprise that many of the firms in the Silicon Valley HDD industry were born from the IBM San Jose operations (see Figure 3). One figure, Al Shugart, an ex-employee of the IBM San Jose Laboratory, was especially important in creating new firms, and his start-ups were also training grounds for a number of the other entrepreneurs who made Silicon Valley the center of the disk drive industry (Christensen, 1992). During the mid-1980s, venture capitalists funded a large number of start-ups especially in Silicon Valley, and many failed spectacularly (Sahlman and Stevenson, 1985; Bygrave and Timmons, 1992).

Because of IBM's presence, a number of the largest HDD firms in the world, i.e. Seagate, Quantum and IBM, are located in Silicon Valley, as are many of the most important suppliers. Not only can the assemblers trace their ancestry back to IBM, but so can the suppliers (Christensen, 1992). For example, Komag, a supplier of disks, was started by an ex-Xerox PARC researcher, two researchers from IBM's laboratory and a manager from yet 


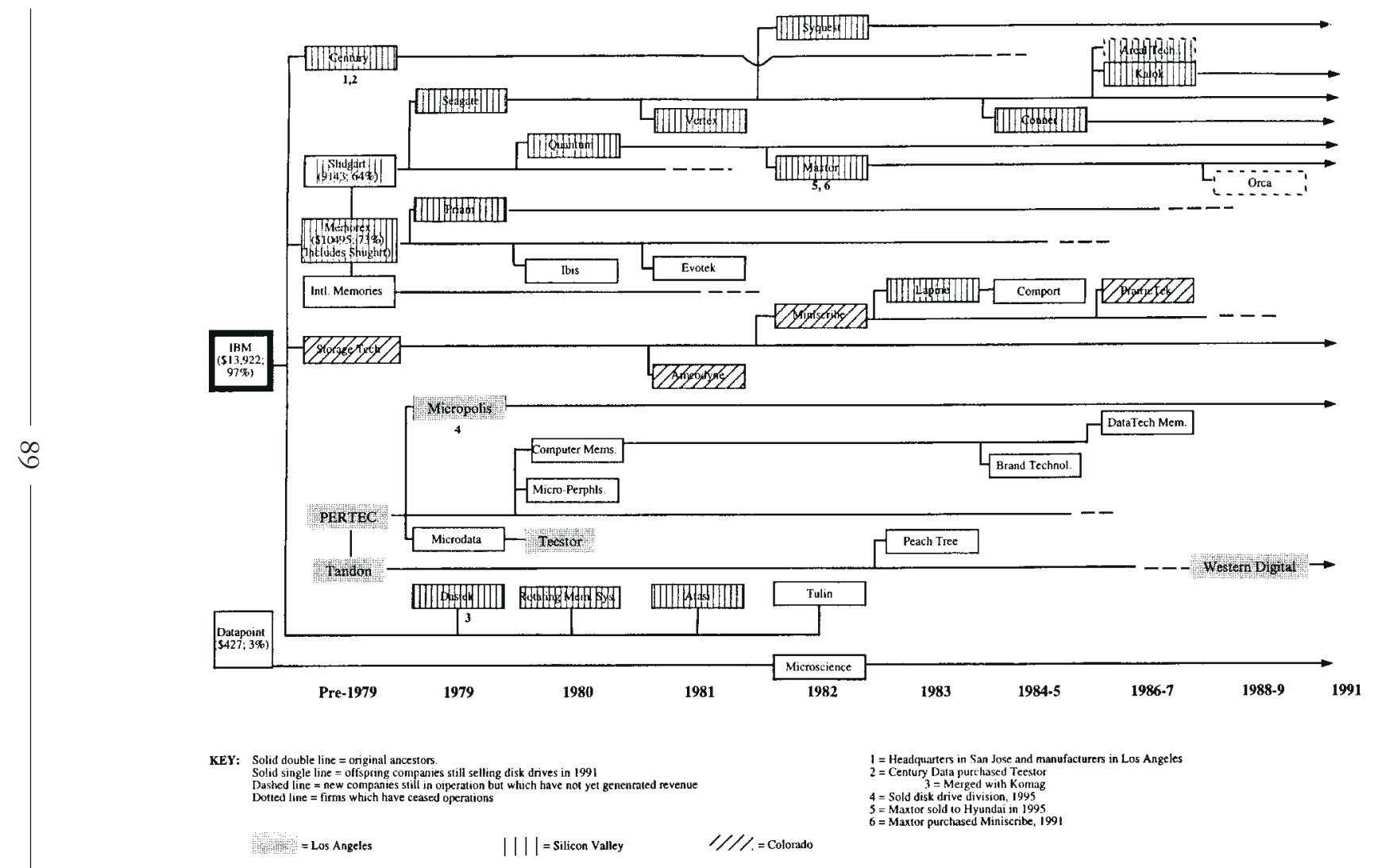

FIGURE 3. Genealogy of start-up disk drive firms. Source: adapted from Christensen (1992, p. 62). 
another company (Komag, Inc., 1996). As important, seemingly whenever there is a new technological innovation or market in the HDD industry, it provides an opportunity for a new firm; almost invariably the firm is formed in Silicon Valley with experienced managers from existing firms. ${ }^{28}$

The IBM San Jose Laboratory also developed the technology for relational databases. However, as was typical for IBM in the 1980s, commercialization was slow. This provided an opportunity for Larry Ellison to found Oracle, which is now the second largest independent software company in the world (Wilson, 1997). With the other two Silicon Valley relational database start-ups, Sybase and Informix, and IBM, Silicon Valley has the largest concentration of relational database software companies in the world. Drawing upon this strength, a number of data warehousing and database mining software firms have spunout. Silicon Valley's Economy 2 converted IBM's seeds into successful and lucrative companies. It is important to note that IBM's other major research laboratories-be they in Tokyo, Yorktown Heights or Zurich—were never hotbeds of new firm spin-offs, but then they were also not located in an environment such as Silicon Valley.

Of all the corporate research laboratories in Silicon Valley, Xerox's Palo Alto Research Center (PARC) has received the most attention and probably contributed the most to Silicon Valley. PARC was established by Xerox in 1970 with the express purpose of doing the basic research necessary to develop the 'office of the future'. Initially there was debate about where to locate the laboratory, but proximity to Stanford and the burgeoning Silicon Valley semiconductor and computer industry convinced George Pake, the first director, to locate in the Palo Alto area (Smith and Alexander, 1988, p. 56). In the 1970s Xerox PARC developed many of the technologies defining computing in the 1990s, including graphical user interfaces, LANs (Ethernet), desktop workstations, the mouse and a number of others. But, as fate would have it, Xerox proved incapable of commercializing these new technologies; however, Silicon Valley's Economy 2 was perfectly capable of funding entrepreneurs to commercialize these seed technologies, often with personnel directly from PARC.

Not all corporate R\&D centers contributed so much to the growth of the Silicon Valley economy. For example, in the 1960s there were a number of laboratories dedicated to military microwave applications. These yielded a

\footnotetext{
${ }^{28}$ An interesting aspect of these fast changing technologies is that so often there is a 'next best thing'. Speaking in 1997 it would have been possible to say that the last HDD startup to achieve dramatic success was Conner Peripherals, which had been established by Finis Conner, a former executive at Seagate. Conner entered the business by specializing in the smaller 3.5 inch form factor that found a ready market in Compaq luggable computers. In 1995 a new company, Terastor, was launched by veterans of other Silicon Valley firms to exploit a new magneto-optical storage technology (http://www.terastor.com).
} 
number of spin-offs, some of which received venture capital funding, but these were not very successful and remained mired in niche markets supplying the military (Leslie, 1993). ${ }^{29}$

One aspect of both regions is their ability to self-correct, because not all apparent opportunities are successful. Many of the most savvy (and stupid) venture capitalists lost large sums on technologies, such as pen-based computing, superminicomputers and artificial intelligence, to name but a few. But after a period of time these firms fail and that technological space no longer receives funding. These failures do not destroy Economy 2 because good venture capitalists have a diverse portfolio and are independent. Even in the worst cyclical downturns, some survive, adapting to new conditions, and in both regions entrepreneurs have repeatedly found lucrative new opportunities, thereby rewarding Economy 2 and creating the resources necessary to repeat the cycle.

Even though the two regions had somewhat different industrial foci, what is as interesting is the consistency with which, as new electronics technologies became commercializable, these two regions were leaders. So, for example, the leading start-up firms in market segments such as workstations and computer networking were formed in Silicon Valley and Route 128. No other regions had major start-ups. In other words, the potential of the new technologies was seen in both regions. Although it is only firms that compete, in most cases, Silicon Valley developed the stronger cluster. The next two sections explore case studies of the development of two different industries-LAN and personal computer assembly_seeking to explain the dynamics of the industry. In the first case, Silicon Valley became the dominant region, and in the second case neither region would dominate the industry.

\section{The Local Area Networking Industry}

These two regions were the centers for the establishment of the LAN industry. Comparing the industry's development in the two regions provides an interesting perspective on the relative divergence in the growth of the two regions in the 1980s. This is more than just a case study, because LANs were the networks that linked computers together in offices and made possible the current computing paradigm of desktop computers and peripherals linked to a network. This section also illustrates the advantages that Silicon Valley was able to draw upon to become the center of the LAN industry. Whereas with semiconductors it was a series of small events clustered around Fairchild's

${ }^{29}$ Leslie (1993) points out that if microwaves had had greater civilian use, Silicon Valley might have been called 'Microwave Valley', because of the large number of small start-ups. 
decisions that ignited a path-dependent process resulting in the clustering of the semiconductor industry in Silicon Valley, in the LAN industry a different set of preconditions heavily influenced the regional clustering of the industry.

The LAN industry as we know it today can be traced to the early 1970 s (Figure 3). At the time there was increasing interest in using rapidly advancing computer technology to 'automate' the office. This 'office of the future' would require a network to share files and expensive peripherals such as printers and hard disks. One leader in this effort was PARC, which in the mid-1970s created a system of desktop computers, laser printers and data storage devices networked by what the inventor, Robert Metcalfe, called Ethernet. PARC was not alone in this effort: nearly all the minicomputer firms and especially Wang Computers were also trying the create the future office. In Silicon Valley Frederico Faggin and Ralph Ungermann left Intel and secured investment from Exxon Corporation to create Zilog, which was also dedicated to creating the office of the future. At Zilog they invented the very successful Z-80 microprocessor and had plans to develop a LAN of their own. This contributed to the lack of a standard and there was a proliferation of incompatible LANs.

From the perspective of providing a standard and significant space for new firm formation in the then inchoate LAN industry, the critical event was Xerox's decision in 1980 to offer low-cost licenses for the Xerox PARC Ethernet standard. To further accelerate Ethernet's acceptance Xerox formed an alliance with DEC and Intel to support Ethernet and to encourage the production of Ethernet-compatible devices (Sirbu and Hughes, 1986; von Burg, 1999). DEC joined because it needed Ethernet to link its VAX computer family. Conversely, DEC's support was an important endorsement that gave Ethernet credibility and encouraged start-ups to believe a market would emerge. Intel was included because Ethernet could not be implemented without sophisticated integrated circuitry. Xerox's licensing objective was to encourage the development of Ethernet-compatible products, so as to lower costs and accelerate adoption. It planned to supply laser printers and other accessories for the networks. The open licensing was a deliberate policy aimed at taking advantage of the dynamism of entrepreneurship at no cost to Xerox.

Ethernet as a powerful open standard was received warmly by a number of start-ups and having Xerox PARC in Silicon Valley assisted in the knowledge transfer process. In 1979 Ralph Ungermann and Charles Bass left Zilog and formed Ungermann-Bass, whose purpose it was to build LANs for large corporate clients. In 1978 Robert Metcalfe left Xerox PARC and in 1979 started $3 \mathrm{Com}$ in Silicon Valley. Figure 4 indicates that in rapid succession 


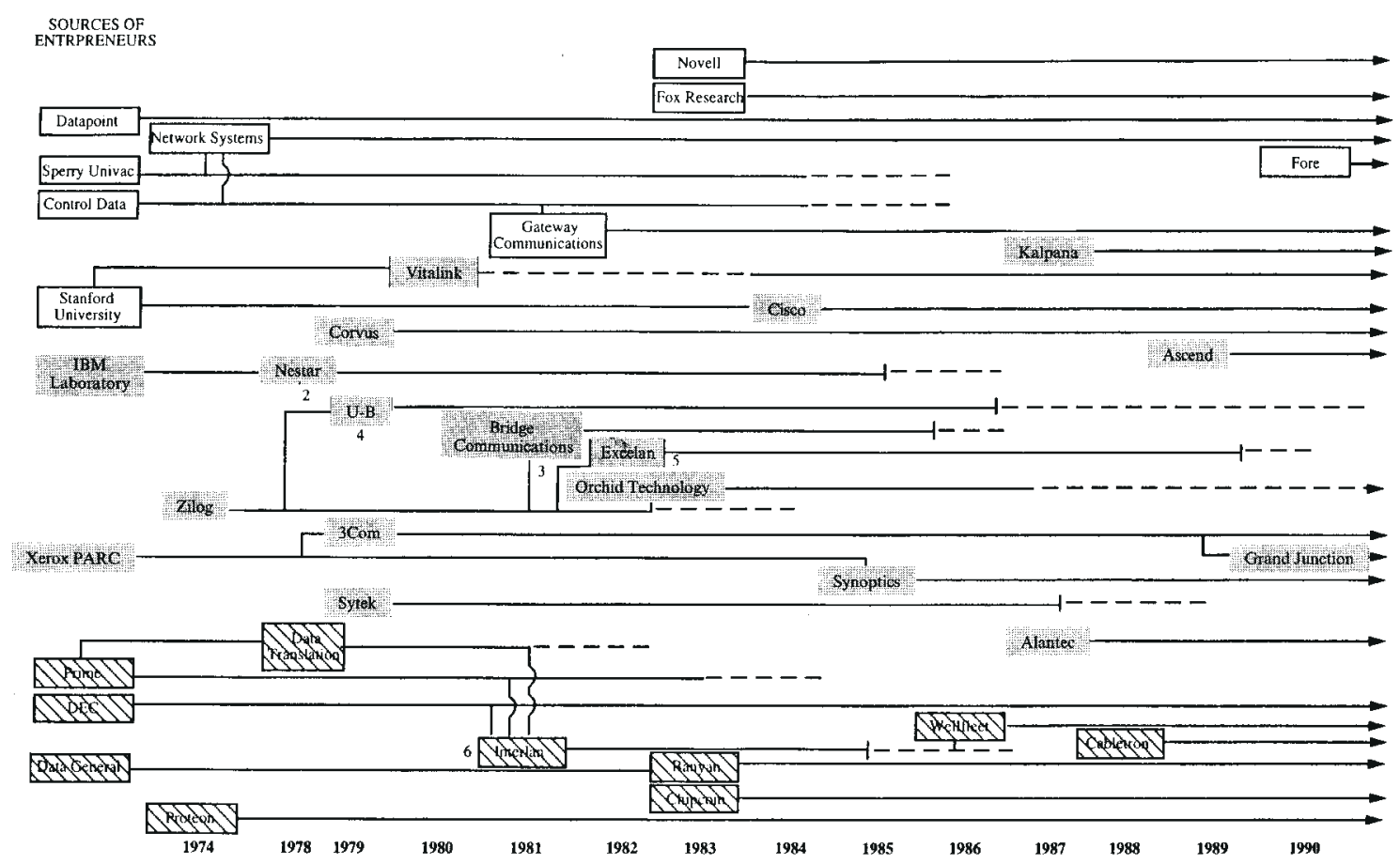

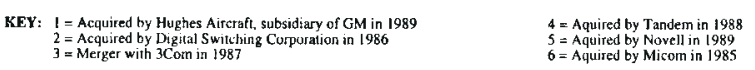

FIGURE 4. Genealogy of start-up LAN firms. Source: compiled by authors. 
Zilog lost two more groups of entrepreneurs. These firms formed the core of the Silicon Valley LAN industry and all were committed to Ethernet. By 1985 there were at least 40 LAN firms. The Bay Area had 11 companies, Southern California had seven firms (none survived to become important players) and Massachusetts had eight firms. No other states had more than four companies, and none of these would prove to be important players.

In the mid-1980s two important LAN firms were established in Silicon Valley. In 1985 Synoptics spunout of PARC and developed a technical solution, the hub, that solved difficult Ethernet wiring problems. The other firm, Cisco Systems, was a Stanford University spin-off that developed the multiprotocol router. Both firms were very successful. The router and the hub established Silicon Valley as the center of the LAN and the LAN-WAN connection industries; interestingly the most important competitors for these firms were headquartered in Route 128.

Route 128 had fewer seed institutions than did the West Coast. There were two significant strands of LAN start-ups in Route 128. The first can be traced to MIT's experimentation with Token Ring LAN technology. Proteon, which was founded in 1974 as a data communications consultancy, entered the LAN business in 1979 and began selling Token Ring LANs in 1981. Although IBM would adopt Token Ring, the market for Token Ring products never grew as large as the Ethernet market. Some Boston area LAN companies exploited the Ethernet standard, but in every case were slightly late to the market. Cabletron, which had been providing Ethernet cabling, simply integrated into the hub business and became the second largest hub provider after Synoptics. Another Boston firm, Chipcom, was founded in 1983 to enter the Ethernet market and was quite successful, but grew slower than the Silicon Valley companies and was purchased by 3Com in 1995 .

The other important strand of the Route 128 LAN industry was the entrepreneurial group composed of Paul Severino and William Seifert. In late 1981 they established Interlan, which aimed to provide Ethernet products to minicomputer firms, such as DEC and Data General. However, Interlan missed the desktop market, as did Ungermann-Bass, and was sold in 1985. Severino and Seifert went on to establish Wellfleet Communications in 1986, which entered the multiprotocol router market where it competed with Cisco. In 1994 Wellfleet was purchased by Synoptics.

Several conclusions can be drawn from this brief overview. First and foremost, Silicon Valley had two critical seed institutions, Zilog and Xerox PARC. PARC was especially important because it developed the Ethernet protocol that ultimately became the standard and concentrated many of the most experienced experts in Silicon Valley. Second, as both path dependence 
and dominant design research has shown, early entry into the correct technological trajectory is an important strategic advantage. Third, though Silicon Valley ultimately captured most of the LAN and computer networking industries, Boston was the only other region that had any significant number of important firms. It is unlikely that Boston's failure to capture this industry is due to organizational or interfirm relations problems. A far more plausible and parsimonious explanation is that a path-dependent dynamic was launched that created a more powerful virtuous circle of growth and advantage reinforcement in Silicon Valley. Fourth, and probably of somewhat less importance, the concentration of semiconductor firms in Silicon Valley provided proximity to the producers of a critical component.

Economy 2 is predicated upon discovering market discontinuities created by technological advances. The participants in Economy 2 are constantly on the alert for just such opportunities. The relative centralization of data communications in Silicon Valley and, to a lesser degree, Route 128 meant that entrepreneurs and venture capitalists were sensitized to see the opportunities possible due to Internet privatization. This is an example of how Economy 1 produces the seeds for Economy 2. Being at the center of the commercialization of leading-edge technology means that it is more likely than not that the new seeds will be most visible to practitioners in those firms intimately related to the technology. This appears to have been the case in the commercialization of the Internet, which a recent newspaper article claimed is 'reshaping the Valley' (Pelline, 1996).

\section{The One that Got Away: Microcomputers ${ }^{30}$}

The locational dynamics in the microcomputer industry provide important insights into the strengths and weaknesses of these regional economies. As we saw in the discussion of Route 128, most criticism of the failure to anticipate and take advantage of the microcomputer has fallen upon DEC and the other Route 128 firms. A more interesting question is why Silicon Valley did not become a center of the microcomputer industry, even though it had the headquarters for firms producing most of the important components, had an active community of microcomputer hobbyists, and had an entire economy predicated upon establishing leading-edge, high-technology firms.

In contrast to Route 128 , which never really had much activity in the microcomputer field, Silicon Valley was a hotbed of start-ups with the locus the now famous Homebrew Computer Club that met at Stanford University

\footnotetext{
${ }^{30}$ We use the term 'microcomputers', until IBM's introduction of the personal computer.
} 
(Freiberger and Swaine, 1984; Langlois, 1992). In the late 1970s Silicon Valley was the center of microcomputer industry and other regions were declining in importance. Nonetheless, the constituents of Economy 2 were initially slow in embracing the microcomputer business. Also, some early leaders such as Processor Technology refused funding (Freiberger and Swaine, 1984, p. 214). However, in other locations there was even less support for microcomputer entrepreneurs.

Apple Computer was the most strategic of the small start-ups. Steven Jobs and Steven Wozniak (more Jobs than Wozniak) decided to build their small start-up into a more substantial firm. To do this they deliberately set out to tap the resources of Economy 2. Jobs talked to Nolan Bushnell, his former employer and the founder of Atari, about who to contact to secure venture capital. Bushnell recommended Donald Valentine, a former Fairchild and National Semiconductor marketing executive who had become a successful venture capitalist. Valentine referred Jobs to Michael Markkula, a former Fairchild and Intel engineer who had become wealthy from his Intel stock options. After meeting Jobs and Wozniak, Markkula decided to invest in Apple and joined the company in 1976. Markkula used his contacts, and in January 1978 Apple received venture capital from VenRock, the venture capital arm for the Rockefeller family, Donald Valentine and Arthur Rock (Young, 1988, p. 151). This rather detailed account illustrates the microlevel personal connections critical to finding and consummating deals. Soon after the Apple financing other microcomputer firms such as Commodore and Osborne Computers also received venture capital.

The late 1970s and early 1980s were an interesting period. There was a continuing proliferation of microcomputer start-ups with Silicon Valley as the industry center. New firms were being established to provide microcomputer software and components. Then in August 1981 IBM introduced its PC which rapidly became the dominant design; nearly all the non-IBMcompatible microcomputer firms in Silicon Valley and other parts of the country disappeared. Within three short years most Silicon Valley microcomputer firms, with notable exception of Apple, left the business.

For IBM it would prove to be a pyrrhic victory, as much of the value-added in the PC accrued to a Silicon Valley firm, Intel, that made the microprocessor and to Microsoft, a Seattle area firm, that controlled the operating system (Curry and Kenney, forthcoming). Since IBM did not control the operating system or the microprocessor, and these could be purchased in the open market, other firms were able to enter the PC industry. The first company to do this was Compaq Computer, which was launched in Dallas, Texas by ex-Texas Instruments engineers and funded by a Dallas-area venture capital 
fund. Over the years there would be a number of other PC companies formed, some of which would be tremendously successful, such as Dell Computer and Gateway 2000, and some that were successful initially and then had difficulties, e.g. AST, Tandon and Packard Bell. Curiously, Silicon Valley would not host any new PC companies (Angel and Engstrom, 1995). ${ }^{31}$

With the exception of Apple, the microcomputer industry did not survive in Silicon Valley, though Silicon Valley firms found lucrative niches supplying many components such as microprocessors (Intel and AMD), BIOS chips (AMI, Phoenix Technologies, and Chips and Technologies), graphics chips (S3, Nvidia, Cirrus Logic), HDDs (Seagate, Quantum and Conner Peripherals) and even computer mice (Logitech and Kensington). Other more standardized components, such as monitors, floppy disk drives (though first commercialized in Silicon Valley by Shugart, they are now almost exclusively produced by Japanese firms), DRAMs, keyboards, power supplies, printed circuit boards and other components, are for the most part produced by foreign firms.

Silicon Valley had every advantage to become the center of the microcomputer industry. There was tremendous interaction and information sharing among the early firms, many suppliers of critical parts, and all of the strengths Economy 2 brings to create new firms and industries, but this did not result in a viable PC industry. The reason is not a lack of flexibility, problematic firm interaction, an excessively rigid culture or the lack of opportunity for large capital gains. Rather, IBM's entry into the market created the focal point around which a dominant design was created. The modular architecture of the PC meant that the technology and design value-added in a PC moved to the components (Langlois and Robertson, 1992, 1995). The PC business now hinged on marketing and managing the logistics system (Steffens, 1994; Curry and Kenney, forthcoming). PC assemblers were not technology developers, they were technology customers. The PC entrepreneurs were Rod Canion and the group of Texas Instruments engineers that started Compaq in Dallas, Michael Dell, the founder of Dell Computer in Austin, Texas, and Ted Wiatt of Gateway Computer in Fargo, North Dakota. The modular nature of the PC compartmentalized the technological value-added away from the assembly process, thus vitiating Silicon Valley's great advantage.

Economy 2's support was insufficient to overcome IBM's dramatic entry and the markets' decision to adopt the PC as standard. After this Silicon Valley

\footnotetext{
${ }^{31}$ The exception is Hewlett Packard, which gained significant PC market share in the mid-1990s. However, with the exception of HP and Apple few Silicon Valley high-technology firms have been successful in consumer markets.
} 
entrepreneurs did not seek to enter the PC business, even though it proved to be tremendously lucrative. The PC did not have the attributes of a typical Silicon Valley product. Not in touch with average consumers and seeing that there was little opportunity to add technological value, the PC business held little attraction for Silicon Valley entrepreneurs.

\section{Discussion}

We disputed explanations for the differential success of Silicon Valley and Route 128 based on culture or on intra- and interfirm organizational characteristics. Rather we found that the technological trajectories of the semiconductor and minicomputer industries were critical for the differential success of the two regions. However, simply attributing the entire history of the regions to their technologies would be naïve. There were critical agents in both regions that intervened to help create history. In Silicon Valley there was Frederick Terman of Stanford University and in Boston there were the visionaries who created and managed ARD. We also highlighted the involvement of seed institutions such as universities and corporate research laboratories such as Xerox PARC and IBM's San Jose facilities. Such institutions played an important role in the development of both regions.

This study found path dependency and its emphasis on the role of small events useful in describing how paths are created and the reasons for subsequent clustering. For example, if Shockley had located his company in Route 128, it is likely that the Fairchild scenario would have occurred there. It seems a great stretch to believe that the new firm formation process would not have occurred in Boston. The initial funding for Fairchild came from the East Coast not the West Coast; the individuals were for the most part not from California, there was venture capital in the Boston area; and there were engineers who were not averse to becoming wealthy. There is little doubt that a spin-off process would have been set in motion, and it is unlikely that the technological trajectory would have been less dramatic. Besides, there is ample evidence of the spin-off phenomenon in the Route 128 area before the minicomputer industry stabilized.

The introduction of the distinction between the established institutions of Economy 1 and institutions dedicated to creating new firms, Economy 2, provided a useful heuristic for orienting our analysis. Here, we drew upon earlier works by Schoonhoven and Eisenhardt (1989), Florida and Kenney (1988a) and Bahrami and Evans (1995) that explicitly focused on the entrepreneurial dimensions of Silicon Valley. These economies are not entirely separate, and there is a path-dependent evolutionary interaction between 
them. It is also quite clear that over time Economy 2 in Silicon Valley became more powerful and, not surprisingly, in the process became richer in speciation terms, than did its Route 128 counterpart. It is difficult to firmly establish causation; however, in both regions Economy 2 lowered the barriers to establishing firms, and repeated spin-offs created a pattern or path for future spin-offs. In fact, the dynamics of Economy 2 creates its own trajectory; the participants 'produce' the new firms, so they have a concrete stake in celebrating entrepreneurship. Put simply, they need and feed the entrepreneurs. Viewed from the perspective of having vibrant Economy 2 s, these regions are more alike than they are different.

The organization of Economy 1 and interfirm relationships among established firms does not explain Silicon Valley's success and Route 128's relative lag. Their firms can have close and interactive relationships or conflictual relationships with suppliers. They can be hierarchically managed like Intel or more horizontally managed like Hewlett Packard. The critical point is whether technologies and innovations being developed can be extruded from these Economy 1 firms to be actualized in new firms through the institutions of Economy 2. There were simply more seeds, more opportunities, and more successes in Silicon Valley. The result was a positive feedback loop that reinforced Silicon Valley and allowed it to outstrip Route 128.

There have been many, mostly unsuccessful, attempts to reproduce Silicon Valley and Route 128 type economies in the USA and around the world. Usually, these have been conceived by government officials and local land developers. But, for all of them, it has been difficult to duplicate the organic, learning-path-dependent evolution replete with learning-by-doing and, most especially, by failure. Moreover, often the characteristics of regional industrial competencies do not exhibit a pattern optimized for the fast-moving semiconductor, data communications and computer industries. This provides grounds for some pessimism regarding policies aimed at cloning these economies. However, there are also grounds for optimism. The Internet and the increasing opportunities reliance on software mean that there is a proliferation of opportunities. This growth of opportunities is given further evidence by the increasing number of venture capital partnerships emerging in other regions of the USA. If this pattern persists the past described here may also be a prologue.

\section{Acknowledgements}

The authors thank David Angel, James Curry, Richard Florida, Richard Langlois, Joel West and Richard Nelson for comments. 


\section{References}

Aldrich, H. and C. Fiol (1994), 'Fools Rush In? The Institutional Context of Industry Creation,' Academy of Management Review, 19, 645-670.

Angel, D. and J. Engstrom (1995), 'Manufacturing Systems and Technological Change: The US Personal Computer Industry,' Economic Geography, 71, 79-102.

Arthur, W. B. (1994), Increasing Returns and Path Dependence in the Economy. University of Michigan Press: Ann Arbor.

Bahrami, H. and S. Evans (1995), 'Flexible Re-cycling and High-technology Entrepreneurship,' California Management Review, 37, 62-89.

Baldwin, C. and K. Clark (1995), 'Sun Wars: Competition within a Modular Cluster, 1985-1990,' Harvard Business School Working Paper no. 95-084.

Borrus, M. and J. Zysman (1997), 'Globalization with Borders: The Rise of Wintelism as the Future of Global Competition,' Industry and Innovation, 4, 141-167.

Braudel, F. (1982), The Wheels of Commerce. Harper \& Row: New York.

Braun, E. and S. Macdonald (1982), Revolution in Miniature: The History and Impact of Semiconductor Devices. Cambridge University Press: Cambridge.

von Burg, Urs (1999), 'Plumbers of the Internet: The Creation of the Local Area Networking Industry,' Ph.D. dissertation, St Gallen University, Switzerland.

Bygrave, W. and J. Timmons. (1992), Venture Capital at the Crossroads. Harvard Business School Press: Boston, MA.

Christensen, C. (1992), 'The Innovator's Challenge: Understanding the Influence of Market Environment on Processes of Technology Development of the Rigid Disk,' DBA dissertation, Harvard University.

Christensen, C. (1997), The Innovator's Dilemma: When New Technologies Cause Great Firms to Fail. Harvard Business School Press: Boston, MA.

Cringely, R. (1996), Accidental Empires. Harper Business: New York.

Curry, J. (1993), 'The Flexibility Fetish: A Review Essay on Flexible Specialization,' Capital and Class, Summer, 99-126.

Curry, J. and M. Kenney (forthcoming), 'Beat the Clock: Time in the PC Industry,' California Management Review.

David, P. (1986), 'Understanding the Economics of QWERTY: The Necessity of History,' in W. Parker (ed.), Economic History and the Modern Economist. Basil Blackwell: New York.

Deutermann, E. (1966), 'Seeding Science-based Industry,' Federal Reserve Bank of Philadelphia Business Revew, May, 3-10.

Dorfman, N. (1982), 'Massachusetts' High Technology Boom in Perspective,' Center for Policy Alternatives, MIT, Cambridge, MA, Working Paper CPA 82-2.

Dorfman, N. (1983), 'Route 128: The Development of a Regional High Technology Economy,' Research Policy, 12, 299-316.

Dorfman, N. (1987), Innovation and Market Structure. Ballinger: Cambridge, MA.

Dosi, G. (1984), Technical Change and Economic Transformation. Macmillan: London.

Dosi, G., F. Malerba and L. Orsenigo (1994), 'Evolutionary Regimes an Industrial Dynamics,' in L. Magnusson (ed.), Evolutionary and New-Schumpeterian Approaches to Economics. Kluwer: Boston, MA, pp. 203-229.

Flamm, K. (1988), Creating the Computer. Brookings Institution: Washington, DC. 


\section{Technology, Entrepreneurship and Path Dependence}

Florida, R. and M. Kenney (1988a), 'Venture Capital-financed Innovation and Technological Change in the USA,' Research Policy, 17, 119-137.

Florida, R. and M. Kenney (1988b), 'Venture Capital and High Technology Entrepreneurship,' Journal of Business Venturing, 3, 301-319.

Florida, R. and M. Kenney (1991), 'Organizational Transplants: The Transfer of Japanese Industrial Organization to the US,' American Sociological Review, 56, 381-398.

Florida, R. and M. Kenney (1999), Financiers of Innovation: Venture Capital, Technological Change and Industrial Development. Unpublished manuscript.

Florida, R. and M. Kenney (1990), The Breakthrough Illusion: Corporate America's Failure to Move from Innovation to Mass Production. Basic Books: New York.

Foray, D. (1991), 'The Secrets of Industry Are in the Air,' Research Policy, 20, 393-405.

Freiberger, P. and M. Swaine (1984), Fire in the Valley. Osborne/McGraw-Hill: Berkeley, CA.

Garud, R. and A. Kumaraswamy (1993), 'Changing Competitive Dynamics in Network Industries: An Exploration of Sun Microsystems' Open Systems Strategy,' Strategic Management Journal, 14, 351-369.

Gilder, G. (1989), Microcosm. Basic Books: New York.

Gilder, G. (1996), 'Feasting on the Giant Peach,' Forbes ASAP, August 26.

Granovetter, M. (1985), 'Economic Action and Social Structure: The Problem of Embeddedness,' American Journal of Sociology, 91, 481-510.

Hall, J. and M. Barry (1990), Sunburst: The Ascent of Sun Microsystems. Contemporary Books: Chicago, IL. Hannan, M. and R. Freeman (1989), Organizational Ecology. Harvard University Press: Cambridge, MA.

Hanson, D. (1982), The New Alchemists. Little, Brown: Boston, MA.

Hardy, Q. (1998), 'Meeting Jerry Weisman, Acting Coach to CEOs,' Wall Street Journal, April 21, B1, B8.

Hekman, J. (1980), 'The Future of High Technology Industry in New England: A Case Study of Computers,' New England Economic Review, January/February, 5-17.

Henderson, R. and K. Clark (1990), 'Architectural Innovation: The Reconfiguration of Existing Production Technologies and the Failure of Established Firms,' Administrative Science Quarterly, 35, 9-30.

von Hippel, E. (1988), The Sources of Innovation. Oxford University Press: New York.

Intel Corporation (1984), A Revolution in Progress. Intel Corporation: Santa Clara, CA.

Karlgaard, R. (1997), 'Present at the Creation,' Forbes, July 7, 274-280.

Kenney, G. (1992), Riding a Runaway Horse. Little, Brown: Boston, MA.

Kenney, M. (1986), Biotechnology: The University-Industrial Complex. Yale University Press: New Haven, CT.

Kidder, T. (1981), The Soul of the New Machine. Avon Books: New York.

Kogut, B., G. Walker and D.-J. Kim. (1991), 'The Role of Large Firms in the Entry of Start-ups: Centrality and Cooperation in the Semiconductor Industry,' Reginald H. Jones Center for Management Policy Strategy and Organization, The Wharton School Working paper no. 91-02.

Komag, Inc. (1996), 'The First Five Years,' Komag: Milipitas.

Kuhn, S. (1982), Computer Manufacturing in New England. Joint Center for Urban Studies of MIT and Harvard University: Cambridge, MA.

Langlois, R. (1992), 'External Economies and Economic Progress: The Case of the Microcomputer Industry,' Business History Review, 66, 1-50.

Langlois, R. and P. Robertson (1992), 'Networks and Innovation in a Modular System: Lessons from the Microcomputer and Stereo Component Industries,' Research Policy, 21, 297-313.

Langlois, R. and P. Robertson (1995), Firms, Markets and Economic Change. Routledge: London.

Leslie, S. (1993), The Cold War and American Science. Columbia University Press: New York. 
Levering, R., M. Katz and M. Moskowitz (1984), The Computer Entrepreneurs. New American Library: New York.

Liles, P. (1977), Sustaining the Venture Capital Firm. Harvard University, Management Analysis Center: Cambridge, MA.

Lindgren, N. (1969), 'The Splintering of the Solid State Electronics Industry,' Innovation, 8, 2-16.

Lowen, R. (1992), 'Exploiting a Wonderful Opportunity: The Patronage of Scientific Research at Stanford University, 1937-1965,' Minerva, 30, 391-421.

Lynn, L., N. Reddy and J. Aram (1996), 'Linking Technology and Institutions: The Innovation Community Framework,' Research Policy, 25, 91-106.

Malecki, E. (1991), Technology and Economic Development: The Dynamics of Local, Regional and National Change. Longman: London.

Malone, M. (1995), The Microprocessor: A Biography. Telos: Santa Clara, CA.

Markusen, A., P. Hall, S. Campbell and S. Deitrick (1991), The Rise of the Sunbelt. Oxford University Press: New York.

Moore, G. (1965), 'Cramming More Components onto Integrated Circuits,' Electronics, April 19, $114-117$.

Moritz, M. (1984), The Little Kingdom: The Private Story of Apple. William Morrow: New York.

Mueller, F. and R. Loveridge (1995), 'The "Second Industrial Divide"? The Role of the Large Firm in Baden-Wurttemberg Model,' Industrial and Corporate Change, 4, 555-82.

Nelson, R. (1998), 'The Co-evolution of Technology, Industrial Structure, and Supporting Institutions,' in G.

Dosi, D. Teece and J. Chytry (eds), Technology, Organization, and Competitiveness. Oxford University Press: New York, pp. 319-335.

Nelson, R. and S. Winter (1982), An Evolutionary Theory of Economic Change. Harvard University Press: Cambridge, MA.

Olsen, K. (1983), Digital Equipment Corporation: The First Twenty-five Years. The Newcomen Society in North America: New York.

Pelline, J. (1996), 'Networking Industry Reshaping the Valley,' San Francisco Chronicle, March 26, C1, C5.

Piore, M. and C. Sabel (1984), The Second Industrial Divide. Basic Books: New York.

Porter, M. (1990), The Competitive Advantage of Nations. Free Press: New York.

Reid, T. R. (1984), The Chip. Touchstone Books: New York.

Rifkin, G. and G. Harrar (1988), The Ultimate Entrepreneur. The Story of Ken Olsen and Digital Equipment Corporation. Contemporary Books: Chicago, IL.

Riordan, M. and L. Hoddeson (1997), Crystal Fire. Norton: New York.

Roberts, E. (1991), Entrepreneurs in High Technology. Oxford University Press: New York.

Robertson, P. (1995), Review of Regional Advantage by AnnaLee Saxenian, Journal of Economic History, 55, 198-199.

Robertson, P. and R. Langlois (1995), 'Innovation, Networks and Vertical Integration,' Research Policy, 24, 543-562.

Rogers, E. and J. Larsen (1984), Silicon Valley Fever. Basic Books: New York.

Romanelli, E. (1987), 'New Venture Strategies in the Minicomputer Industry,' California Management Review, Fall, 166-175.

Rose, F. (1989), West of Eden: The End of Innocence at Apple Computer. Penguin: New York.

Rosegrant, S. and D. Lampe (1992), Route 128: Lesson's from Boston's High Tech Community. Basic Books: New York. 
Schaller, B. (1996), 'The Origin, Nature, and Implications of "Moore's Law", http://www.research. microsoft.com/ Gray/Moore_Law.html.

Saxenian, A. (1980), 'Silicon Chips and Spatial Structure,' Masters thesis, University of California, Berkeley. Saxenian, A. (1994), Regional Advantage. Harvard University Press: Cambridge, MA.

Sayer, A. and R. Walker (1992), The New Social Economy: Reworking the Division of Labor. Basil Blackwell: London.

Schoonhoven, C. B. and K. Eisenhardt (1989), 'The Impact of Incubator Region on the Creation and Survival of New Semiconductor Ventures in the US 1978-1986,' Report to the Economic Development Administration, US Department of Commerce (August).

Schumpeter, J. (abridged by Reindig Fels) (1969), Business Cycles. McGraw-Hill: New York.

Scott, O. (1974), The Creative Ordeal: The Story of Raytheon. Atheneum: New York.

Sirbu, M. and K. Hughes (1986), 'Standardization of Local Area Networks,' Working Paper, Department of Electrical Engineering, Carnegie Mellon University.

Smith, D. and R. Alexander (1988), Fumbling the Future. William Morrow: New York.

Steffens, J. (1994), Newgames: Strategic Competition in the PC Revolution. Pergamon Press: Oxford.

Storper, M. (1993), 'Regional "Worlds" of Production: Learning and Innovation in the Technology Districts of France, Italy and the USA,' Regional Studies, 27, 433-455.

Storper, M. and R. Salais (1997), Worlds of Production. Harvard University Press: Cambridge, MA.

Storper, M. and R. Walker (1989), The Capitalist Imperative: Territory, Technology, and Industrial Growth. Basil Blackwell: London.

Stowsky, J. (1987), 'Semiconductor Production Equipment, Linkages, and the Limits to International Trade,' University of California, Berkeley, BRIE Working Paper no. 27 (August).

Sturgeon, T. (1992), 'The Origins of Silicon Valley,' Master's thesis, Department of Geography, University of California, Berkeley.

Suchman, D. (1994), 'On Advice of Counsel: Law Firms and Venture Capital Funds as Information Intermediaries in the Structuration of Silicon Valley,' Ph.D. dissertation, Stanford University.

Tilton, J. (1971), International Diffusion of Technology: The Case of Semiconductors. Brookings Institution: Washington, DC.

Todtling, F. (1994), 'Regional Networks of High-technology Firms-The Case of the Greater Boston Region,' Technovation, 14, 323-343.

Walker, R. (1985), 'Technological Determination and Determinism: Industrial Growth and Location,' in M. Castells (ed.), High Technology, Space and Society. Sage: Beverly Hills, CA, pp. 226-64.

Walker, R. (1988), 'The Geographical Organization of Production-Systems,' Environment and Planning D: Society and Space, 6, 377-408.

Weiss, J. and A. Delbecq (1990), 'A Regional Culture Perspective of High Technology Management,' in M. Lawless and L. Gomez-Meija (eds), Strategic Management in High Technology Firms. JAI Press: Greenwich, CT, pp. 83-94.

Wilson, J. (1985), The New Venturers. Basic Books: New York.

Wilson, M. (1997), The Difference between God and Larry Ellison. William Morrow: New York.

Young, J. (1988), Steve Jobs: The Journey is the Reward. Scott, Foreman: Glenview, IL.

Zucker, L., M. Darby and J. Armstrong (1994), 'Intellectual Capital and the Firm: The Technology of Geographically Localized Knowledge Spillovers,' NBER Working Paper 4946, National Bureau of Economic Research: Cambridge, MA. 